\title{
Justiça Cognitiva e Educação Política
}

\author{
Cognitive Justice and Political Education ${ }^{1}$
}

\author{
João da Cruz Gonçalves Neto \\ Universidade Federal de Goiás, Goiânia - GO, Brasil
}

Resumo: Este trabalho é a apresentação sintética de uma experiência de pensamento: a tentativa de extrair da obra de John Rawls um método de reflexão pública, feita em torno de três problemas centrais: 1) a constituição de um inventário normativo exemplar da atualidade e não apenas a indicação de conceitos teoricamente amadurecidos pela tradição acadêmica; 2) a constituição de um inventário do conhecimento político, de sua forma e estrutura, de natureza autônoma; 3) a constituição de uma hipótese sobre a mudança social a partir dos pressupostos da Teoria da justiça, da noção de justiça cognitiva e da educação política.

Palavras-chave: Reflexão Pública. John Rawls. Epistemologia Política. Justiça Cognitiva. Educação Política.
Abstract: This paper presents syntheticaly an experience of thought: the attempt to construct a method of public's reflexion based on the works of John Rawls. Such try is done around three central problemas: 1) the constitution of the actuality's caracteristics, from common perception; 2) the constitution of the politic's knowledge - its form and estructure, of autonomous nature; 3) the constitution of a hypothesis on social change from the Theory of Justice, from the notion of the cognitive justice and political education.

Keywords: Public Reflexion. John Rawls. Political Epistemology. Cognitive Justice. Experience of Thought.

1 Este trabalho constitui aprimoramento de excerto de tese de doutoramento não publicada, nesta oportunidade patrocinada pelo Edital FAPEG Universal n. 07/2014, e pelo projeto DER2013-47662-C2-2-R, financiado pelo MINECO y FEDER, Espanha (Este trabajo fue realizado tambien en el marco del proyecto DER2013-47662-C2-2-R financiado por el MINECO y FEDER).

Recebido em: 21/08/2013

Revisado em: 28/04/2015

Aprovado em: 30/05/2015 
A história é fecunda e aberta a possibilidades tanto quanto pode ser o futuro idealizado.

\section{Introdução}

Em nossa tese de doutoramento (GONÇALVES NETO, 2006), procurou-se extrair da obra de John Rawls um aspecto que não se encontra substantivamente indicado, mas decisivamente implicado por sua Teoria: da sua forma e desenvolvimento é possível extrair um conjunto de princípios e de procedimentos, pela maneira como se situa na tradição acadêmica, pelos pressupostos que ele assume, pela maneira como persegue seus fins, que se constitui como um discurso orientado indiretamente para o fundamento de qualquer ação e reflexão públicas, e não só para critérios de distribuição de bens, como um método que se apropria da dinâmica própria do pensamento público e o converte em sabedoria política. A esse discurso do método político, ou teoria normativa do conhecimento políti$c o$, ou ainda sabedoria política, é que se pensa constituir um instrumento de crítica social por excelência, mesmo que não desenvolvido em todas as suas possibilidades, mesmo que seja apenas um método formal. Mas de que forma essa estrutura argumentativa dirigida a fundamentar critérios de distribuição de bens pode consistir numa crítica? Pretende-se desenvolver a extração do método da obra de Rawls em torno de três problemas centrais: 1) a constituição de um inventário normativo exemplar da atualidade, e não apenas a indicação de conceitos teoricamente amadurecidos pela tradição acadêmica; 2) a constituição de um inventário do conhecimento político, de sua forma e estrutura, de natureza autônoma; 3 ) a constituição de uma hipótese sobre a mudança social a partir dos pressupostos da Teoria da Justiça. Apresentar uma descrição sintética do que foi ali defendido é o objetivo deste texto.

Algumas palavras acerca da metodologia utilizada neste texto são necessárias. Um artigo acadêmico ou científico deve seguir várias regras formais para que avalize seu autor como um interlocutor qualificado entre seus pares. Essas regras, para as ciências humanas, já estão bem assentadas na prática acadêmica nacional e balizam a quantidade 
e qualidade das fontes, a correção linguística, o aspecto formal determinado pelas regras da ABNT, a coerência e linearidade argumentativa, bem como a relevância e novidade do tema abordado para que seja aproveitado no diálogo comum de especialistas. A maior parte de nossos veículos acadêmicos seguem com rigor essas orientações, para o bem da produção intelectual brasileira.

Todavia, menos comuns são os textos experimentais, que se propõem a ser diálogos criativos com os autores e com a tradição, e com isso buscando uma liberdade formal maior que geralmente a tolerada pela prática academia comum. Com razão, esses trabalhos criativos são vistos com suspeita, pois com muita frequência podem ser apenas aventuras autistas em busca de visibilidade, sem dar garantias de um anterior trabalho hermenêutico sério.

Por outro lado, sem a prática criativa, mesmo com seus riscos, jamais se deixará de ser apenas um bom estudante.

Esse texto é uma aventura experimental. Ele pretende constituir-se metodologicamente como um diálogo qualificado com a teoria da justiça de John Rawls, extraindo-lhe alguns pressupostos para constituir outra coisa não pretendida por aquele autor, que é a teoria normativa do conhecimento público. Evidentemente que essa apresentação esquemática guarda em si uma necessidade de ulterior desenvolvimento e expansão, tanto em sua temática quanto no enriquecimento de suas fontes. Em última instância, esse texto mira na construção dos fundamentos de uma epistemologia política, que se situe autonomamente entre a filosofia, a ciência e a sociologia políticas. Esse é, todavia, um trabalho para o futuro.

O método experimental, assim, nos fez produzir um recorte de um projeto maior. Nessa oportunidade, é possível assumir os elementos essenciais da filosofia política do autor de Uma teoria da justiça para, do interior dela, elaborar o que se considera uma extensão de seu alcance. Em nome da agilidade de raciocínio, nessa empresa permite-se algumas poucas licenças metodológicas, sem, como se crê, comprometer a fidelidade às fontes. Assim, mesmo sendo um recorte experimental, espera-se que este texto se constitua leitura útil e provocativa. 


\section{A Teoria Normativa do Conhecimento Público}

Quando são apresentadas as concepções de filosofia política defendidas ou implicadas na obra de Rawls, atribui-se a ela dois papéis fundamentais: o papel especulativo de ampliação conceitual, intuitivo, que tem a função de aumentar a objetividade política pelo aumento da objetividade cultural; e o papel prático de fornecer um método, um esquema normativo ao pensamento político, que sirva de amparo às deliberações concretas, de forma a se ter um corpo de conhecimento público cumulativo e sistemático que ao mesmo tempo se aproprie da experiência histórica e explicite os ideais latentes da sociedade. (RAWLS, 2003a, p. 2-5)

Essa concepção de filosofia como sabedoria prática, portanto, será assumida como uma teoria sobre a atualidade e sobre um método de reflexão e deliberação políticas que se constituem mais como um conjunto de princípios e forma de análise (a sabedoria política) que um algoritmo elaborado para dar estabilidade e segurança à ação com base em algum pressuposto externo ao sistema. A essa teoria (extraída da concepção de filosofia política para Rawls) chama-se de discurso do método político.

O discurso do método político é uma teoria sobre a atualidade. A atualidade é mais do que a realidade social e mais do que uma convenção sobre princípios políticos. É certa maneira de uma cultura se refletir em diferentes níveis de representação, por meio de discursos que se imbricam e se situam no interior de um continente cognitivo, não explícito em seus conteúdos. Sem elementos fixos aos quais se referir, a própria autorreflexão e o desvelamento daquele continente semântico constituirão o elemento sólido necessário à deliberação pública; o reconhecimento dos limites à reflexão e à ação nos faz ser menos ambiciosos quanto às nossas pretensões históricas e nossa capacidade de gestão da própria vida, tanto quanto nos extrai do ponto de vista particular (do indivíduo não situado), e, portanto, das condições que predispõem ao dogmatismo, à crença irrefletida, ao ardor habitual pelas pretensões de verdade e de realidade.

A constituição de uma estrutura conceitual normativa extraída da cultura de fundo da sociedade em questão pode ser, então, uma sólida, mas flexível base para a reflexão e deliberação políticas. A esses concei- 
tos que, reunidos, formarão a atualidade no aspecto político, chamar-se-á de metafísica normativa. A metafísica normativa não é uma metafísica especulativa, mas somente um inventário dos conceitos abstratos utilizados pela cultura para representar-se, conceitos esses tomados em sua acepção comum, e cuja objetividade será estabelecida exatamente pelo seu uso habitual incorporado nas práticas quotidianas. Esses conceitos abstratos são chamados por Rawls de concepções-modelo ${ }^{2}$, e por nós serão chamados de axiomas políticos ${ }^{3}$; ao invés de intuídos, eles são colhidos, prospectados do fundo da cultura. É nessa base conceitual normativa que residirá a segurança interna do método, que por ser instrumental, ser operada pelas regras de raciocínio e coerência interna publicamente aceitas, será chamada de cogito político, a segurança aos procedimentos públicos que não podem se apoiar em representações secundárias das partes. A forma como se definem esses conceitos é essencial para a compreensão da teoria, e constitui um problema à parte o procedimento de sua constituição.

\section{Princípios Extraídos da Teoria da Justiça de Rawls}

Mencionou-se que a teoria cognitiva da política é derivada da Teoria da Justiça pela evidência de alguns pressupostos que são tomados como hipóteses de trabalho. A primeira hipótese é a que afirma que a Teoria da Justiça é um modelo de fundamentação epistêmica da política e, assim, ela é precebida por algumas de suas características: a sua concepção prática da filosofia política, que se volta à complexidade interna da vida social, assumindo a atualidade nos seus aspectos históricos e cognitivos, suporta uma postura metodológica flexível, liberal, que faz do

2 " $[. .$.$] A teoria da justiça como equidade tenta descobrir as ideias fundamentais (latentes$ no bom senso) relativas à liberdade, à igualdade, à cooperação social ideal e à pessoa formulando o que eu chamarei de concepções-modelos [...] As duas concepções básicas na teoria da justiça como equidade são as de uma sociedade bem ordenada e de uma pessoa moral". (RAWLS, 2000b, p. 53)

3 As concepções-modelo de Rawls são por mim rebatizadas de axiomas políticos. Axiomas pelo fato de constituírem elementos sobre os quais se erigirá uma estrutura política normativa, e cuja consistência será testada pela coerência do método. São elementos indemonstráveis politicamente, embora razoavelmente evidentes quando extraídos corretamente da autorrepresentação pública. 
concreto a referência central de seu afazer prospectivo; o seu liberalismo é um tanto conservador, que faz da política uma espécie de tradição raciocinada de certa atualidade, que busca nessa mesma atualidade as suas regras e modos de existir; os seus pressupostos epistemológicos, mesmo dispensando a especulação aberta e negativa, são constituídos sobre a autorreflexão situada. A posição original é o enquadramento cognitivo que determinará a objetividade política, quando instaura a unidade reflexiva e equipara as partes, situando-as, quando admite o tipo e medida de conhecimento em seu ambiente, quando traduz a realidade social em conceitos normatizados e, assim, forma o quadro metodológico que se julga constituir a teoria do saber político como sabedoria.

A segunda hipótese é a que afirma que é possível se extrair um método de reflexão pública, como parte da teoria que tenta conferir à política um âmbito específico e diferente do da ciência e da filosofia, e que deriva de duas outras características fundamentais da Teoria da Justiça, a saber, a que implica em uma hipótese sobre a mudança social e a que implica na hipótese da especificidade de um conhecimento público. A mudança social é vista em Rawls ${ }^{4}$ (por todo o seu esforço em fundamentar uma teoria da justiça social) como a constante busca da confirmação dos ideais nas instituições, uma vez que nenhuma injustiça social se manteria sob o desvelamento de uma realidade em confronto com os ideais que, na distância, ajudam a mantê-la. Portanto, para a tradição liberal à qual Rawls se filia, não será a cisão abrupta da realidade a melhor maneira para a mudança, mas a busca do equilíbrio entre os elementos que constituem a atualidade, a saber, a realidade representada historicamente e os ideais que a animam como possibilidade ${ }^{5}$. A segunda intuição a que se refere foi

4 Como uma "teoria dos sentimentos morais", a justiça como equidade mantém-se na mais estrita tradição liberal, aquela que pretende buscar a legitimidade política numa base moral igualitária e democrática. (WALDRON, 1987, p. 140). Assim expressa uma consonância com esse projeto: "I want to present liberalism as [...] a theory about what makes political action [...] morally legitimate. The thesis that I want to say is fundamentally liberal is this: a social and political order is illegitimate unless it is rooted in the consent of all those who have to live under it; the consent or agreement of these people is a condition of its being morally permissible to enforce that order against them".

5 A mudança social em Rawls não é concebida pelo confronto das visões de mundo em busca de hegemonia, pois a justiça não está à mercê de interesses e necessidades 
a de que a natureza da reflexão individual difere da natureza da reflexão pública. E assim se dá esse saber coletivo: pelo confronto atual e histórico dos pontos de vista individuais; por sua concepção instrumental de verdade; pelos fins estabelecidos em virtude dos interesses coletivos; pela compreensão da atualidade na história e nunca no interior dela mesma; por suas operações se darem no plano de representação pública. Enfim, com certa noção de mudança social realizada pela realização dos ideais nas instituições atuais e com uma visão própria do conhecimento político como autônomo (de outros saberes) e coletivo (não reduzido ao individual), é que se estrutura o método como parte da teoria do conhecimento político, cujos elementos foram estabelecidos previamente.

\section{O Método}

Percebeu-se, em outra ocasião, que o discurso do método político, ou teoria normativa do conhecimento político, é composto pela metafisica normativa, pelo cogito político e pelo método de reflexão pública, que se poderia definir como a forma de reunir, na instância e no interesse do político, os limites da cultura, a forma de raciocínio, os elementos e a forma de apreendê-los na história, nas ciências, na tradição e na crítica da contingência. Como enumeradas em escritos anteriores, as funções desse método, ou seja, as tarefas às quais se incumbiria são duas, a saber, a cognitiva e a deliberativa, cujos conteúdos serão sintetizados em seguida.

\subsection{A Tarefa Cognitiva (a dinâmica do método)}

Como se pensa, a tarefa cognitiva do método consistiria em 1) estabelecer o que seja o conhecimento público e sua estrutura; 2) demonstrar

concretas. Ela é prefiguradora desses interesses, e guia-se por objetivos de longo alcance. Ela define um ponto de Arquimedes (equilíbrio) para a avaliação do sistema social, sem invocar considerações apriorísticas. O ritmo de mudança e as reformas específicas que são necessárias dependem das condições existentes (RAWLS, 1997b, p. 289). A virtude, então, é vista como um elemento de estabilidade do sistema, e a mudança é sempre concebida como reestruturação interna, mas nunca como cisão abrupta. Não há outra alternativa além das condições vistas da atualidade. 
a especificidade do conhecimento público; 3) estabelecer os critérios da justiça sob os ideais latentes na sociedade.

\subsubsection{O Conhecimento Público e sua Estrutura}

Define-se o conhecimento público essencialmente como reconhecimento de três elementos centrais, a saber, do foco objetivo na autorrepresentação pública, ou seja, o reconhecimento do conceito hegemônico na auto representação pública, do centro da dinâmica das relações em torno da qual tudo se pauta; da dinâmica social auto representada, ou seja, o reconhecimento da atualidade, de sua estrutura, em confronto com outras atualidades; e, por fim, da distinção entre o ponto de vista individual e o público, com o reconhecimento da diferença de suas naturezas.

O reconhecimento implica no inventário da estrutura do conhecimento público, da qual se enumeram alguns elementos, como segue.

O mundo social como representação - em nossa cultura as pessoas pensam viver em dois níveis de representação: o primário (subcontingente), que consiste no conhecimento concebido num modelo que o vê como duplicação do mundo; e o secundário (contingente), notadamente o nível das atuações sociais, que duplica o primeiro nível. O objeto da política liberal e das relações sociais é a representação secundária do mundo e da sociedade. Como se pensa, mesmo os princípios de justiça (de distribuição de bens) de Rawls foram concebidos para esse segundo nível de representação. Há uma representação e uma operação própria da coletividade: a auto representação pública e a reflexão pública.

Níveis de representação e o indivíduo - os indivíduos encontramse, geralmente, em meio a uma confusão representativa. Grosso modo (provisoriamente), poder-se ia afirmar que a reflexão individual se dá em níveis superpostos de experiências ou apreensões representativas em campos semânticos indevidos, o que faz da história individual de vida uma história (real) de descaminhos, caótica, assumida assim sob o rótulo da liberdade. Esses níveis narrativos são concebidos em nossa representação pública da seguinte maneira: o transcendental (como função social), o existencial, o histórico, o coletivo, o particular, o intelectual não linguístico e o intelectual linguístico. 
Suspensão histórica - a suspensão histórica é o estado de incerteza do indivíduo com relação às regras sociais válidas, às expectativas do que ele pode esperar do grupo, em se saber se e como o conhecimento é uma mediação válida, em se saber o que a atualidade abriga para o futuro, em se saber sob que condições e forma a identidade pública e do indivíduo são criadas, percebidas como real, uma vez que elas próprias são duvidosas.

Focos objetivos - em nosso mundo representado as relações sociais costumam se dar em torno de um aspecto dominante, que submete outras dimensões da vida e dinâmica públicas. A vida social, as relações morais, jurídicas e políticas se enfeixam em uma noção chave: o foco objetivo. Se a objetividade cognitiva indica a abertura de certa atualidade à complexidade da vida social, o foco objetivo é o elemento ao qual se reduz muito da abrangência cognitiva da atualidade. Quanto maior for a abertura objetiva de uma cultura, mais o foco objetivo tende a se pluralizar, a se diluir em aspectos mais ricos e diversificados da vida humana, mais complexos, portanto. Em nossa atualidade (atual, pela ideologia vigente), o foco objetivo constitui-se nas relações econômicas, cujo domínio sobre outras relações sufoca e oprime várias outras expectativas e vivências guardadas na possibilidade dos ideais e faz da vida privada um caos onde vige o estado da suspensão, precariedade e doses volumosas de auto ilusão. A esse estado de indefinição e provisoriedade focada corresponde ao que se chama de despotismo cognitivo, que é a aglutinação e reconhecimento nas instituições políticas e sociais de todas as esferas da vida, como se o mundo fosse unidirecional e unilinear.

Razão pública - é o enquadramento institucional do ideal de sociabilidade democrática, igualitária e justa. Ela é constituída a partir do melhor raciocínio dentro de regras validadas pela experiência social comum, pelas regras comuns de inferência, pela experiência científica e pelas condições abstratas advindas da simulação dos ideais políticos, como uma referência pública para as relações políticas incorporadas nas instituições vigentes. Se a política é um dos focos objetivos possíveis em nossa cultura, a razão pública é o foco objetivo da política. 
Normatividade - é a forma atual de se apreender a realidade e arbitrar coletivamente significados instrumentais, provisórios. Por sua autorreferência, é a segurança do método.

Indivíduo - as concepções liberais do indivíduo e da sociedade são concepções judaico-cristãs. O indivíduo é dotado de uma identidade com garantia transcendental e atua (como ator) num palco pleno de possibilidades. Para tanto, sua "consciência" constitui um recuo intelectual, o que lhe garante a ideia de autonomia e liberdade. Retirada a justificação transcendental, é essa a noção que Rawls ${ }^{6}$ se apropria e de onde deve partir sua normatização, uma vez que é a noção partilhada por nossa cultura. Ao papel especulativo do método cabe, então, tentar ampliar a objetividade que contém essa estreita noção.

Ambientes reflexivos - como alguns dos elementos do pensamento público, há ainda os ambientes emocionais (e reflexivos). Além das frações representativas que constituem o mundo social, os indivíduos vivem em ambientes emocionais que submetem a sua racionalidade. Como produto social, ele próprio constitui uma fração de uma representação maior, a coletiva, da qual participa de forma semiconsciente ou mesmo inconsciente, vivendo usualmente uma vida emocional e intelectual fragmentada, incompleta, provida com abastança de ilusões traduzidas como fins morais particulares e como elementos de coesão social. Afirma-se, em texto anterior, que o nascimento político do indivíduo acontece quando o seu ambiente emocional e intelectual não é compreendido, mas compreende o ambiente coletivo quando ele, depois de perdê-lo, volta a ter a

6 Eis um enunciado de sua concepção instrumental de pessoa: "Desde o mundo antigo, o conceito de pessoa foi entendido, tanto pela filosofia quanto pelo direito, como o conceito de alguém que pode tomar parte ou desempenhar um papel na vida social e, por conseguinte, exercer e respeitar seus vários direitos e deveres. Assim sendo, dizemos que uma pessoa é alguém que pode ser um cidadão, isto é, um membro normal e plenamente cooperativo da sociedade por toda a vida" (RAWLS, 2000a, p. 61). Em outros termos: "The rational plan for a person determines his good. Here I adapt Royce's thought that a person may be regarded as a human life lived according to a plan. For Royce an individual says who he is by describing his purposes and causes, what he intends to do in his life [...]" (RAWLS, 1997b, p. 408). "The term is given no technical sense, nor are the structures of plans invoked to get other than obvious common sense results. These are matters I do no investigate". (RAWLS, 1997b, p. 408) 
familiaridade com o mundo. É somente quando pode ocorrer a sua racionalidade dentro de limites comuns que pode haver ações e deliberações em afinidade com o foco objetivo e a elevação do ponto de vista individual ao ponto de vista coletivo, dirigida àquele foco.

Sabedoria política - ela se dá pelo confronto atual e histórico dos pontos de vista individuais ou de grupos, resultando em algo possivelmente do maduro raciocínio individual; sua concepção de verdade é instrumental; seus fins são estabelecidos em função de interesses coletivos, embora preservando interesses individuais; suas ações são voltadas para além da atualidade, e guiadas por uma pluralidade de focos objetivos; os argumentos e decisões políticas deverão ser necessariamente públicos.

\subsubsection{A Especificidade do Conhecimento Público: a dinâmica cognitiva}

Em nossa atualidade, o indivíduo situa-se em dois mundos, o da representação primária e o da representação secundária. Ele vive, geralmente, ou confuso, ou iludido, ou totalmente absorvido por seu papel funcional, ou ainda nesses três estados ao mesmo tempo, com respeito à ideia que tem de si e dos outros. Essa confusão cognitiva vem do estado de suspensão, de incerteza e de precariedade do mundo, por um lado advindas das condições de vida concreta, por outro pela manipulação das ilusões por forças oportunistas que espontaneamente se aproveitam da desorientação pública (e que vão chamar de liberdade). Além da vida dos indivíduos se desenrolarem em ambientes emocionais diferentes e contidos no ambiente público, de superporem os níveis de representação, confundindo-os, há ainda a redução do foco objetivo a limitar a possibilidade de realização e de expansão vivencial humana?

O nascimento político do indivíduo para a ordem que o compreende no nível de representação secundária e que amplia a sua vivência pelo reconhecimento dos fatores que determinam o seu ponto de vista e sua própria identidade, é objeto da reflexão política como sabedoria.

Para tanto, há a constituição de um discurso público referencial que visa a dar a segurança instrumental tanto às deliberações políticas quanto

7 De acordo com os ideais públicos atuais. 
às pessoais, utilizando-se dos focos objetivos encontrados na cultura. Em uma atualidade liberal, o foco objetivo se dá na política (idealmente, embora realmente se dê no domínio pelas relações econômicas) e estabelece as relações sociais representadas publicamente em noções normativas extraídas da visão comum e habitual do mundo. Esse rol de conceitos normatizados (a metafísica normativa) constituirá a referência pública ao imaginário coletivo e às instituições políticas, consolidadas na razão pública.

O discurso público constitui, assim, a unidade reflexiva e representativa indispensável ao afazer político, o ambiente comum que dispõe as partes em um só nível representativo e foco reflexivo, constituindo, com isso, o sujeito político. A partir dessa unidade, tem-se que as principais tarefas da política, em sua função cognitiva, são, a saber, a constituição pelo reconhecimento do saber político, e a formulação das noções de justiça, seja a voltada para a atualidade (por exemplo, critérios de distribuição de bens), seja para a que transcende a atualidade, a justiça cognitiva - a que elabora as condições de nivelamento cognitivo entre as partes e amplia, especulativamente, a objetividade política, o tamanho do mundo dentro da atualidade em que se situam as partes.

\subsubsection{Critérios de Justiça sob os Ideais Latentes da Sociedade: a justiça cognitiva}

Outra tarefa cognitiva da política é a do reconhecimento (ou construção) de critérios de justiça. Muito mais que o estabelecimento de critérios para distribuição de bens (feito por Rawls), o método de reflexão política prevê a justiça cognitiva. A demanda por essa justiça, assim, nasce da necessidade de se definir o que pode ser objeto de compreensão e ação políticas e o que não pode; para tanto, deve-se definir o que pode ser conhecido, estabelecendo-se um solo de compreensão comum, para que desses limites se extraiam alguma certeza estratégica, um modo de ver comum que garantirá o firmamento de princípios de conhecimento e ação contra o acaso e sua utilização como instrumento de controle de uns indivíduos e grupos sobre outros. Nessa acepção, a justiça seria, assim, a garantia de um solo comum, o estabelecimento de um plano cognitivo, a equanimização de ambientes entre os agentes (tal como na posição original), para que esses tenham reais condições de reflexão e deliberação. 
Os fins da justiça cognitiva são, enfim: definir e desvelar o foco reflexivo como um dos vários possíveis; demonstrar os fundamentos epistemológicos partilhados pela cultura em seus vários níveis; explicitar os problemas da atualidade em seus vários campos (científico, filosófico, político); inventariar a realidade social, em suas várias acepções (quais e como os processos históricos a constituem e os modelos de conhecimento respectivos); demonstrar como se define o indivíduo em meio ao sistema social, qual a natureza das relações, qual sua localização existencial; explicitar as regras de pensamento e expressão linguísticas comuns, ensinar genericamente os saberes considerados por Rawls como necessários na posição original para a formação do cidadão e para a deliberação política ${ }^{8}$. Ao se tentar promover essa justiça, será efetivada também a tarefa especulativa tradicional da filosofia política, que é a da tentativa de transcendência de contextos, de abertura cognitiva e de imaginação crítica.

\subsection{A Tarefa Deliberativa (a ação política)}

Como se pensa, a tarefa deliberativa do método consistem: 1) na constituição do sujeito político; 2) na busca do equilíbrio entre os elementos da atualidade visando à ação; 3 ) em promover a justiça cognitiva constituindo um programa de educação política.

\subsubsection{A Constituição do Sujeito Político}

É preciso estabelecer, primeiro, as diferenças entre o ponto de vista individual e o ponto de vista público. Em primeiro lugar, a visão abrangente individual (ou das partes) procura por respostas globais agora, premidas pela busca de justificação definitiva de uma ação ou critério de ação; visa ao máximo de conhecimento sobre um objeto ou complexo de objetos, e, no entanto, é sempre uma experiência reflexiva, externa, que tenta manter o conhecedor o mais incólume possível; a consciência do indivíduo (sua identidade) se amplia com mais conhecimento; o indivíduo

8 " [...] It is taken for granted, however, that they know (the parties) the general facts about human society. They understand political affairs and the principles of economic theory; they know the basis of social organization and the laws of human psychology. Indeed, the parties are presumed to know whatever general facts affect the choice of the principles of justice”. (RAWLS, 1997, p. 137) 
conhece por modelos racionais, que são sempre limitados e provisórios; ele, o indivíduo, vive em suspensão histórica, que é uma indefinição e uma precariedade natural à forma como representa o mundo e a si mesmo sobre o que constitui a sua própria experiência de vida; ele pode, no entanto, reconhecer-se em um modelo amplo, representativo, partilhado num plano específico, o político, e deixar outras possibilidades de existência em suspensão, até que encontrem experiência e expressão; a $e d u$ cação política, que tem por base os limites máximos da representação pública, é que seria o instrumento desse reconhecimento representativo e da constatação de outras possibilidades de experiência. Em segundo lugar, o modelo de concepção da realidade social do conhecimento público é formal e histórico; ele constitui o domínio representativo comum o mais amplo possível, dentro da possibilidade de partilhamento conceitual em algum nível; sua estrutura normativa é meramente referencial, pois se a assume apenas como suporte para a liberdade não simplesmente conceitual, mas como um sistema aberto de experiências e de pensamento; pressupõe-se, com isso, que haja outras formas de experiências de vida (que não o conhecimento conceitual), e que a experiência política deve ser aberta a outras possibilidades de vida (e não só porque a justiça é o primeiro dos bens sociais e pode garantir a estabilidade); a interação social remodela os ímpetos abrangentes, dando origem a algo diferente do querido e visto pelas partes; somente uma estrutura formal de conhecimento público pode apreender a exterioridade do alcance reflexivo do indivíduo.

Além dessas distinções, é possível observar que, no nosso método de reflexão pública, a abstração é concebida de forma diferente daquela imaginada por nossa cultura ao sujeito epistêmico: em nosso modelo, a abstração não é realmente um recuo intelectual, um aparte temporal que permite conhecer, mas antes um render contas do passado, um inventário interno da reflexão, uma constituição de uma realidade pública a partir de uma experiência intelectual, de uma ideia que se introduz em um arranjo de coisas já destinado a ela. $\mathrm{O}$ âmbito de reflexão pública é ele mesmo o conhecimento interno, sua auto constituição, que se presta como única referência à deliberação e à ação. Em termos cognitivos, o maior desafio político é a constituição do próprio sujeito político, como foco racional 
do qual emana o lugar reflexivo e a referência aos princípios e limites do conhecimento público.

\subsubsection{A Busca do Equilibrio Prático entre os Elementos da Atualidade}

Afirma-se que a deliberação política parte de certa visão da realidade social normativa pressuposta no modelo da posição original, e situa-se no equilíbrio entre a análise histórica e a busca de efetivação de ideais coletivos. Defende-se com a tradição moderna da política (que passa por Maquiavel e Rawls) que a correta análise da experiência atual sobre o passado, somada à imaginação filosófica e à busca de ideais latentes na cultura de fundo, perfaz todo o aparato de gestão da vida política. Essa é a capacidade dos agentes políticos na posição original que se transpõe à tarefa política deliberativa: uma capacidade analítica para decompor a atualidade em confronto com a história e a motivação dos ideais que os limites do ambiente reflexivo permitam e que os fazem ser mais que metas individuais. É dessa dinâmica reflexiva que se extrai, também, os elementos de um método de reflexão voltado para a deliberação política.

Entre aqueles dois pilares da ação política, a análise histórica e a busca dos ideais, a ação política deve buscar o equilíbrio, de acordo com a concepção de mudança social que se atribui a Rawls. Grosso modo, esse equilíbrio pode ser exemplificado da seguinte maneira: se houver a ênfase deliberativa nos ideais, poder-se-ia ter como resultado um regime político aristocrático; se houver a ênfase na vida prática, na contingência, haverá de ter a anarquia; se for a tradição a receber o peso reflexivo, aí se terás o conservadorismo; se, finalmente, a ênfase se dá no equilíbrio reflexivo, poderse-ia ter a democracia constitucional igualitária e aspirando à justiça.

\subsubsection{A Promoção da Justiça Cognitiva a partir da Educação Política}

A equanimização cognitiva e a constituição do sujeito político são tarefas políticas que condicionam, por exemplo, a confecção de princípios de justiça. Mas o que seria essa equanimização cognitiva? Equanimizar o conhecimento é fazer com que as partes possam ascender aos elementos mais essenciais da cultura, da civilização, a partir de certo campo significativo, de certo arranjo representativo estabelecido normativamente, e so- 
bre o qual se permite o ajuste institucional, convencional, assim que se alterem aqueles elementos. A correspondência institucional a essa posição na Teoria seria a educação política, universal, essencial, democrática, plural.

Os princípios de nosso modelo de educação política foram baseados no procedimento que Rawls chama de equilíbrio reflexivo ${ }^{9}$. O equilíbrio reflexivo é a postura reflexiva que não se detém em um só arranjo de coisas, mas considera as possibilidades de compreensão e análise de questões em várias atualidades, num processo de autorreflexão compreendido historicamente. Além dessa postura reflexiva, há os saberes substanciais admitidos no modelo do autor americano, a saber, a teoria política, a economia, a sociologia, a história e a psicologia social, que são os saberes verdadeiramente relevantes à sabedoria política, à cidadania, à capacidade de compreender os problemas políticos além dos particularismos ou visões existenciais não situadas. A função essencial de uma educação política, assim, é demonstrar os limites da autorreflexão pública; os condicionamentos epistemológicos e culturais aos quais está submetida a objetividade atual; a localização existencial, emocional, social, econômica e cultural do indivíduo; o confronto da atualidade corrente com outras atualidades na história. Enfim, é elevar o indivíduo à compreensão política da vida social, da realidade como é vista atualmente e em confronto com outras realidades, da fragilidade e provisoriedade dos conceitos que estruturam seu mundo, ou seja, é fazer com que ele perca definitivamente a familiaridade com o mundo.

$9 \mathrm{Na}$ descrição da posição original e da tarefa das partes (cidadãos) em selecionar princípios de justiça dados, pode acontecer de que esses princípios se ajustem às nossas convicções, o que seria bom. Entretanto, pode haver discrepâncias. "In this case we have a choice. We can either modify the account of the initial situation or we can revise our existing judgements, for even the judgments we take provisionally as fixed points are liable to revision. By going back and forth, sometimes altering the conditions of the contractual circumstances, at others withdrawing our judgments and conforming them to principle, I assume that eventually we shall find a description of the initial situation that both expresses reasonable conditions and yields principles with match our considered judgements duly pruned and adjusted. This state of affairs I refer to as reflective equilibrium. (RAWLS, 1997a, p. 20) 


\section{A Ação Política}

O problema da organização social não é primeiramente moral e não envolve simplesmente os sentimentos que movem e acompanham os ímpetos de verdade e de realidade. O problema é que não se tem uma visão pública da forma como se estabelece o conhecimento público, ou se este chega a ser mesmo constituído.

Não é de se pressupor que a sociedade não alcance seus ideais por uma deficiência dos caracteres dos indivíduos, e que a moralidade, como ideal, seja ostensivamente negligenciada por interesses imediatos e particulares. Antes, é de se pensar que o mecanismo que forja os ideais é o mesmo que faz com que eles se concretizem ou não. Compreender ou permitir a reflexão universalizada sobre esse mecanismo é uma tarefa cognitiva pública que interessa e interfere nas relações sociais.

A ignorância sobre o que constitui a realidade pública e as possibilidades de ação e reflexão é que, em vez de riqueza e liberdade, converte-se em força destrutiva e desordenada.

A reflexão pública, então, é a que tem como objeto a constituição do sujeito político por instauração de uma razão pública instrumental, situado dentro de seus limites históricos e cognitivos publicamente reconhecidos; ou seja, a reflexão pública tem a si mesma como objeto.

O conhecimento público é instrumental, pois é somente um dentre outros, e é condicionado pelas formas culturais que lhes deu origem. Não tem a pretensão de definitividade, como a ciência. É um conhecimento que se estabelece a partir de uma reflexão histórica, que se vê em mudança ao longo do tempo.

O conhecimento público instrumental é reflexivo (tem a si mesmo como objeto), representativo (vê-se como uma réplica do mundo e de si) e linguístico.

A tarefa política por excelência é estabelecer um campo de convergência entre tantas visões de mundo entre diferentes planos de formas de existência, em torno de uma representação pública de realidade formada por conceitos normativos extraídos do fundo da cultura pelo trabalho reflexivo. 
Justiça, assim, seria mais que um critério de distribuição de bens em uma sociedade que tem o foco reflexivo na economia; seria antes a universalização do acesso do indivíduo ao plano de representação política. $\mathrm{O}$ artifício da posição original pressupõe essa noção prévia de justiça, antes de elaborar seus critérios de distribuição de bens.

Princípios de justiça da Teoria de Rawls: igualdade, liberdade e autonomia. Esses princípios não são construídos, mas extraídos da cultu$\mathrm{ra}^{10}$. Esses princípios solicitam também critérios de satisfação, a saber, as condições que fizeram da posição original um ideal. Essas condições são a determinação do espaço teórico comum e a elevação do indivíduo aos limites da representação política de mundo.

As doutrinas abrangentes ocorrem em um estado de suspensão histórica, e há a possibilidade dessas doutrinas serem dissociadas não só nos interesses que as dispõem no plano político, mas na forma mesmo como existem. Fornecer uma referência comum é tarefa da política, como construtora de um modelo cognitivo instrumental público.

A vida social é complexa e sua reflexão deixa em suspensão o que não cabe no campo de apreensão da realidade atual (na objetividade política), sob a forma de incerteza, precariedade e liberdade.

Sem uma referência comum aos indivíduos, uma representação coletiva que possa os orientar, essa liberdade torna-se controle e medo.

A questão política é, então, como assegurar que haja unidade cognitiva instrumental, ao instaurar um campo único de reflexão pública, e ao mesmo tempo preservar a diversidade de visões de mundo, em diversos planos de existência. A primeira tarefa consiste na constituição de uma realidade pública normativa; a segunda em preservar a liberdade estabelecida sobre condições básicas de visão de mundo, de equidade cognitiva.

\footnotetext{
10 “As concepções de sociedade e pessoa enquanto ideias da razão não são, evidentemente, construídas, assim como tampouco os princípios da razão prática o são. Mas podemos concebê-las como ideias agrupadas e conectadas. Como acabamos de fazer, podemos refletir sobre a maneira pela qual essas ideias aparecem em nosso pensamento prático e procurar estabelecer uma ordem segundo a qual possam ser relacionadas, partindo da mais genérica e simples para a mais específica e complexa”. (RAWLS, 2000a, p. 154)
} 
Um sistema de reflexão pública instrumental tem por objetivo fornecer uma referência cognitiva ao indivíduo, ao objetivar as condições, constituição e limites do conhecimento público, criando um plano representativo comum que dê ao indivíduo condições de elaborar e fundar critérios de justiça sob certo foco objetivo.

Só assim o caos que engendra precariedade deixa de ser tomado por liberdade; liberdade é consciência dos próprios limites.

A vida não deveria ser um jogo obrigatório e inescapável do qual os participantes devem adivinhar as regras, e têm na morte ou na humilhação pública penas imediatas pelo movimento que provoca a perda relativa. Se essa é a nossa condição existencial, a vida social não tem o direito de replicá-la pelo simples fato de que não é isso o que se quer.

Nosso objetivo e nossa tese: tentar constituir esse sistema de reflexão pública e conhecer como ele opera a representação pública de mundo.

A representação pública, para efetivar-se na democracia, deve ser divulgada universalmente. Ideologia é qualquer representação pública menos abrangente; é também a representação pública atual como explicação última da realidade.

Liberdade é ter condições de se situar e refletir para além das constrições atuais. É transcender contextos sociais, é ter condições de refletir a existência, a vida. Somente uma educação política universal permitirá essas condições.

\section{Conclusão}

Os problemas aos quais se dedica neste e em outros textos correlatos são de epistemologia política. Acredita-se que seja uma área de conhecimento cuja ordem de problemas tem se definido em um novo contexto histórico, depois que as concepções de sociedades atomizadas e orgânicas fizeram milhões de vítimas quando se tornaram programas de governo, e fazem ainda um número ainda incrivelmente maior quando governam a vida psíquica dos herdeiros de uma visão de mundo pouco complexa. 
Os problemas tratados aqui são, assim, não da ordem do poder e de sua institucionalização, mas da ordem que se interessa em saber qual a natureza da apreensão política de mundo; em como se constitui o sujeito político e qual o seu campo de ação; em saber qual a dinâmica do pensamento público e quais seus princípios; em indicar os caminhos formais a partir do desvelamento cognitivo incorporado nas instituições em geral. Hoje, muito dessa abordagem metodológica tem sido empreendida pelos estudos da complexidade. Nosso esforço consiste em apresentar uma proposta política que é antes de tudo epistemológica. Como se pensa, talvez essa seja uma das grandes novidades de nosso século.

\section{Referências}

GONÇALVES NETO, J. C. A sabedoria política: por uma sabedoria do conhecimento público em John Rawls. Porto Alegre: Biblioteca digital de teses e dissertações na PUCRS, 1996. (Inédita)

GONÇALVES NETO, João da Cruz. A sabedoria política: por uma teoria normativa do conhecimento público em John Rawls. Porto Alegre, RS. Tese de doutoramento. Pontifícia Universidade Católica do Rio Grande do Sul - PUCRS, 2006.

RAWLS, John. Uma teoria da justiça. São Paulo: Martins Fontes, 1997a.

. O Liberalismo Político. São Paulo: Editora Ática, 2000a. . Justiça como equidade, uma reformulação. São Paulo: Martins Fontes, 2003a.

. A Theory of Justice. Massachusetts: The Belknap Press of Harvard University Press. 1997b.

. Kantian constructivism in moral theory. The Journal of

Philosophy, Pennsylvania, LXXVII: 515-72, set. 1980.

1996.

. Political Liberalism. New York: Columbia University Press, 
. Justice as fairness, a restatement. Cambridge: Harvard University Press, 2003 b.

. John Rawls Collected Papers. Massachusetts: Harvard University Press, 1999.

. O direito dos povos. São Paulo: Martins Fontes, 2001.

. Justiça e democracia. São Paulo: Martins Fontes, 2000 b.

. Lectures on the History of Moral Philosophy. Cambridge:

Harvard University Press, 2000c.

WALDRON, Jeremy. Theoretical Foundations of Liberalism. The

Philosophical Quarterly, Oxford University Press, v. 37,

n. 147, p.127-150, 1987.

João da Cruz Gonçalves Neto é graduado em Filosofia pela Universidade Federal de Goiás (1989) e em Direito pela mesma Universidade (1998); mestre em Filosofia pela Universidade Federal de Goiás (2000) e doutor em Filosofia pela Pontifícia Universidade Católica do Rio Grande do Sul (2006). Atualmente é professor adjunto II na Universidade Federal de Goiás. Possui experiência na área de Direito, com ênfase em Filosofia do Direito, atuando principalmente nos seguintes temas: direito e arte, teorias da justiça, conflitos agrário-ambientais e direitos humanos.

E-mail: dellacroce@dellacroce.pro.br

Endereço profissional: Universidade Federal de Goiás, Faculdade de Direito Pça. Universitária - Setor Universitário. CEP: 74605-220 - Goiania, GO - Brasil. 
